\title{
MORPHOLOGY AND MICROENCAPSULATION EFFICIENCY OF FOAMED SPRAY-DRIED SUNFLOWER OIL
}

\author{
Artur Lewandowski ${ }^{*}$, Marcin Czyżewski, Ireneusz Zbiciński \\ Technical University of Lodz, Faculty of Process and Environmental Engineering, \\ ul. Wólczańska 213, 90-924 Łódź, Poland
}

\begin{abstract}
An analysis of the effect of feed foaming on the efficiency of sunflower oil encapsulation on selected product properties is presented in the paper. Experiments were carried out in a pilot-plant concurrent spray dryer using the gas-admixing technique. The analysis of the product properties showed that the application of foaming makes it possible to control final product properties, e.g. apparent density, bulk density, distribution of particle diameters, etc. at a high efficiency of sunflower oil encapsulation.
\end{abstract}

Keywords: spray drying, emulsion, microencapsulation efficiency, foaming

\section{INTRODUCTION}

Microencapsulation is a method that allows sensitive ingredients to be physically enveloped in a protective matrix of wall material in order to protect core materials. This method is mainly used to produce packaging for liquids, solids or gases with a thin protective wall, which inhibits volatilisation and protects the material inside. The first publications and patents concerning the process of microencapsulation mainly in the food industry were published about 50 years ago. There many examples of successful implementation of this method in food and pharmaceutical industries for perishable and sensitive products (Adamiec and Marciniak, 2006; Gibbs et al. 1999; Zuidan and Nedović, 2010).

\section{MICROCAPSULE STRUCTURE}

In the microencapsulation process, depending on the method used, one can obtain particles of a different morphology owing to the nature of materials, applied microencapsulation technologies and emulsion properties. According to the description given by Kumar (2006), a microcapsule is composed of a core material (closed) and closing material, having the ability to develop an insulating wall which protects the core material (Benita, 2006).

In the literature related to spray drying one can find an innovative method to control product properties (Chen et al., 2009), through a direct addition of gas $\left(\mathrm{N}_{2}, \mathrm{CO}_{2}\right.$, etc.) to a stream of dried solution foam spray drying. The first experiment in this field, described in 1957 by Sinnamone'a et al., indicated that the foam spray drying of condensed milk produced full cream milk powder with excellent taste and dispersion properties. Hanrahan and Webb (1961) and Hanrahan et al. (1962) obtained stable, 
unbounded whey powder by introducing compressed air into the solution before atomisation. The authors found that foaming affected the properties of the dried particles increasing particle diameter and porosity, which in turn affected the bulk density of the product. No research on microencapsulation foam spray drying has been presented in the literature.

\section{PURPOSE OF THE WORK}

The aim of this study was to investigate the effect of foaming of emulsion on microencapsulation efficiency and selected parameters of the final product after spray drying.

\section{MATERIALS AND METHODS}

\subsection{Wall and core materials}

The wall material applied in the experiments was maltodextrin DE-16 which belongs to a group of skin-forming materials. The core material was sunflower oil (Kruszwica, Poland) and emulsifying agent - Tween-80 (Croda International Plc). The mass concentration of components in the solution was constant, i.e. maltodextrin $20.0 \%$, oil $3.0 \%$ and surfactant $0.3 \%$ which gives core to wall ratio $1: 7$.

\subsection{Emulsion preparation}

The process of preparing the emulsion was as follows. The emulsion was prepared in a tank with a capacity of 1501 equipped with a ribbon stirrer with the speed of 150rpm. The emulsifier and maltodextrin was dispersed in distilled water at the temperature of 45 to $50^{\circ} \mathrm{C}$ and then, sunflower oil was added and emulsification process was carried out using a high speed recirculating pump and homogeniser at the speed of $23000 \mathrm{rpm}$. The process homogenised solution of oil/maltodextrin/water a mechanical Ultra-Turrax T-25's disintegrator (IKA, Germany) (Mongenot, 2000). Time needed to prepare the emulsion was strictly related to the quality of the emulsion. The average time was $2 \mathrm{~h}$. During the emulsification process the temperature of the solution and the degree of oil dispersion were controlled. The droplet diameter in the emulsion was measured by means of the analysis of microscopic photographs using an image analysis program Image-Pro Plus v.4.5.1.29 (Media Cybernetic Inc., USA). The mean oil droplet diameter in the emulsion was 2 to $3 \mu \mathrm{m}$ at the temperature of 45 to $50^{\circ} \mathrm{C}$.

\subsection{Analytical methods}

To investigate particle morphology of the material and basic physical properties of the powder, a FEI Quanta 200F scanning electron microscope (SEM) was applied. The structure of the material was analysed using Image-Pro Plus v.4.5.1.29 (Media Cybernetic Inc. USA). The moisture content of the powder was analysed according to the Polish standard PN-A-74855-4 in an oven at $(105 \pm 1)^{\circ} \mathrm{C}$ for $3 \mathrm{~h}$ in the dryer SVP 4M by WAMED. The pycnometer AccPyc $1330 \mathrm{TC}$ v3, accuracy $\pm 0.03 \%$ was used to determine the apparent density of the powders obtained during spray drying with and without foaming of the raw material (Fuchs et al., 2006). The apparent density was averaged from 10 repetitions.

\subsection{Microencapsulation efficiency}

In order to determine the efficiency of microencapsulation of the samples, weighing $(1 \pm 0.01) \mathrm{g}$, was 
dissolved in $(5 \pm 0.04) \mathrm{ml}$ of water. Oil extraction process was carried out using $(10 \pm 0.04) \mathrm{ml} \mathrm{n}$-hexane. The extraction time was the same for all the processes and equal to $30 \mathrm{~min}$. The total oil content in the microcapsules was measured by the spectrophotometric method using a UV/UV-Vis T80 (PG Instruments Absorbance) at the wavelength $270 \mathrm{~nm}$ (Adamiec and Marciniak, 2006). The photometric accuracy was \pm 0.004 Abs $(0.5 \div 1 \mathrm{~A})$. Each sample was analysed in three trials. Microencapsulation efficiency (Me) was calculated as: (mass of oil in the core of the capsule/total mass of oil) $\times 100 \%$.

\section{EXPERIMENTAL SETUP}

The process of microencapsulation for non-foamed and foamed emulsion was conducted in a co-current pilot plant spray dryer equipped with an emulsion foaming system. The height of the spray drying tower was $\sim 8 \mathrm{~m}$ and the chamber diameter was $0.5 \mathrm{~m}$. A mono pump (Moyno, USA) transported the feed solution to the nozzle (Fig. 1). A pressure nozzle LN - 1 from Spraying System Company (USA) was used to atomise thesolution. The nozzle was installed on top of the column. The tunnel was equipped with a measuring system that controlled all basic parameters of the drying process and properties of the liquid. The degree of homogeneity of the mixture was controlled using a density meter $( \pm 0.1 \%)$ (Micro Motion $2400 \mathrm{~S}$ Emerson, USA). During the spray drying process the inlet air temperature was changed in the range from 150 to $200^{\circ} \mathrm{C}$, while the outlet air temperature ranged from 79 to $120^{\circ} \mathrm{C}$.

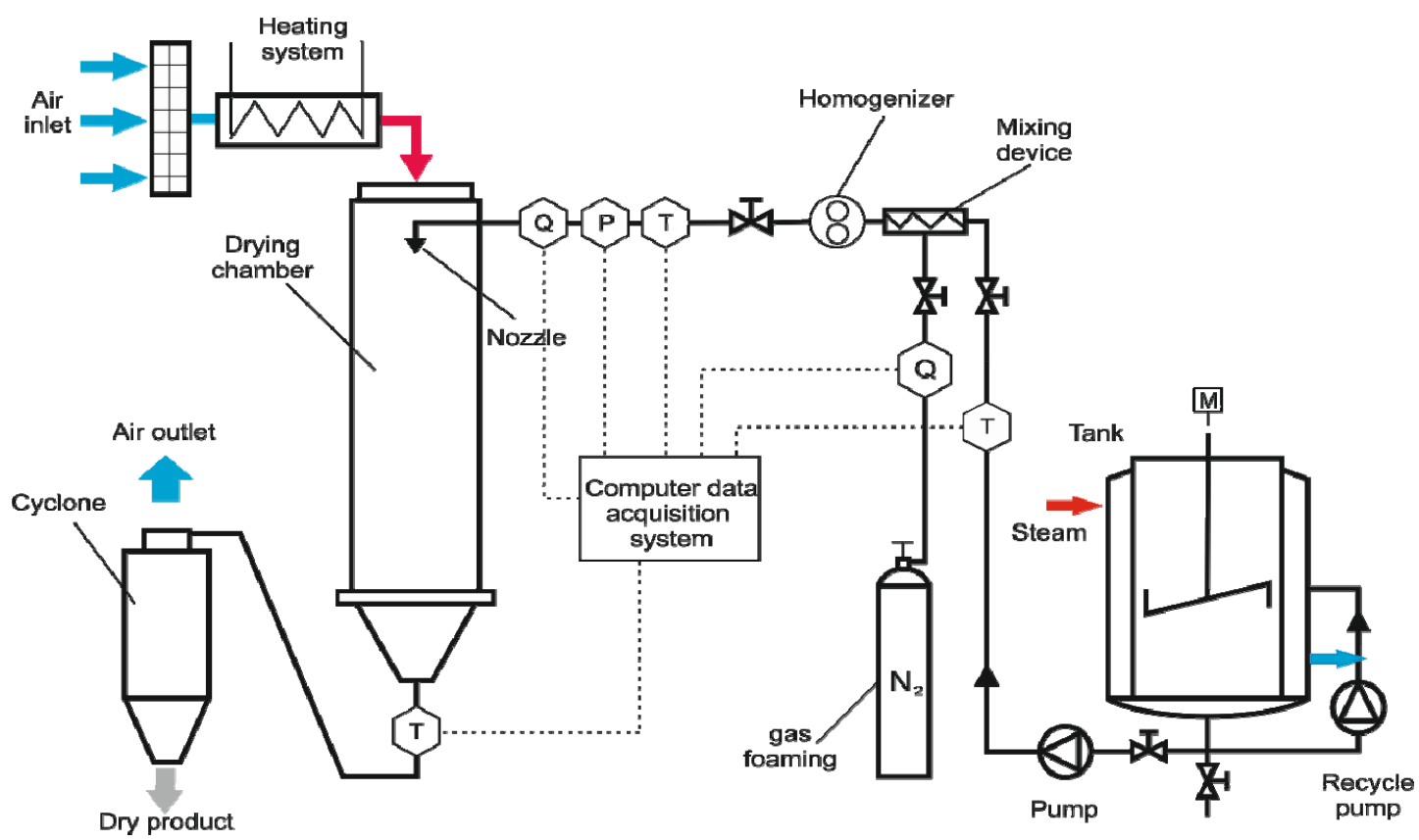

Fig. 1. Scheme of the experimental equipment

The flow rate of drying air was $\sim 300 \mathrm{Nm}^{3} / \mathrm{h}$ and the mass flow of the spray solution was constant and equal to $9.0 \mathrm{~kg} / \mathrm{h}$. Dry material was conveyed to a cyclone. The process of foaming the emulsion was based on a direct addition of nitrogen to the raw material by means of a mixing device. The process of foaming was controlled by a digital mass flow controller DMS KOBOLD (Austria) with the accuracy of $( \pm 1 \%)$. Nitrogen was added of the feed at the flow rate of $0.02,0.04,0.075 \mathrm{~kg} / \mathrm{h}$. The main elements of the foaming system included a gas-liquid static mixing system and a homogeniser IKA MAGICLAB (Germany). The gas and feed were supplied to the mixing device to maintain uniform gas distribution in the liquid. The gas/emulsion mixture was homogenised continuously to obtain a uniform mixture of gas in the sprayed emulsion. In order to produce a homogeneous solution of oil/solution/gas, 
a mechanical Ultra-Turrax T-25's disintegrator (IKA, Germany) with a S25KV-25F dispersing element was used. Gas bubbles were disintegrated at the speed of $23000 \mathrm{rpm}$ which allowed us to obtain a homogeneous gas/emulsion mixture.

\section{RESULTS AND DISCUSSION}

\subsection{Properties of the non foamed products}

To determine the effect of gas foaming on selected properties of microcapsules, basic physical properties of the powder were determined. In the first step, the properties of the powder obtained during spray drying without gas foaming were analysed. Figure 2 shows morphology of the microcapsules received during drying of the emulsion at the following conditions: $Q_{r}=(9.1 \pm 0.2) \mathrm{kg} / \mathrm{h}$, $T_{\text {in }} / T_{\text {out }}=(150 \pm 2.5 / 96 \pm 1.5)^{\circ} \mathrm{C}$ and $T_{\text {in }} / T_{\text {out }}=(201 \pm 2.6 / 114.6 \pm 2.1)^{\circ} \mathrm{C}$. Figure 2 (a, b) shows spherical particles typical for spray drying of skin forming material.

We may observe an increase of arithmetic mean particle diameters from 28.8 to $38.4 \mu \mathrm{m}$ and Sauter mean diameter $S M D$ from 47.9 to $56.1 \mu \mathrm{m}$ caused by swelling of voids trapped in the particles during atomisation. Microencapsulation efficiency of sunflower oil in maltodextrin was determined in three consecutive trails for different drying conditions.

The microencapsulation efficiency (Me) values reflect the presence of oil inside the wall material of encapsulated particles. The microencapsulation efficiency for non-foamed spray varied from 87 to $65 \%$ depending on temperature. Figure $2(a, b)$ show the places of sunflower oil occurrence not trapped in the material, in points A, B, C. Table 1 illustrates the microencapsulation efficiency of the spray drying process for all the analysed material, apparent density for different drying temperatures and emulsion density.
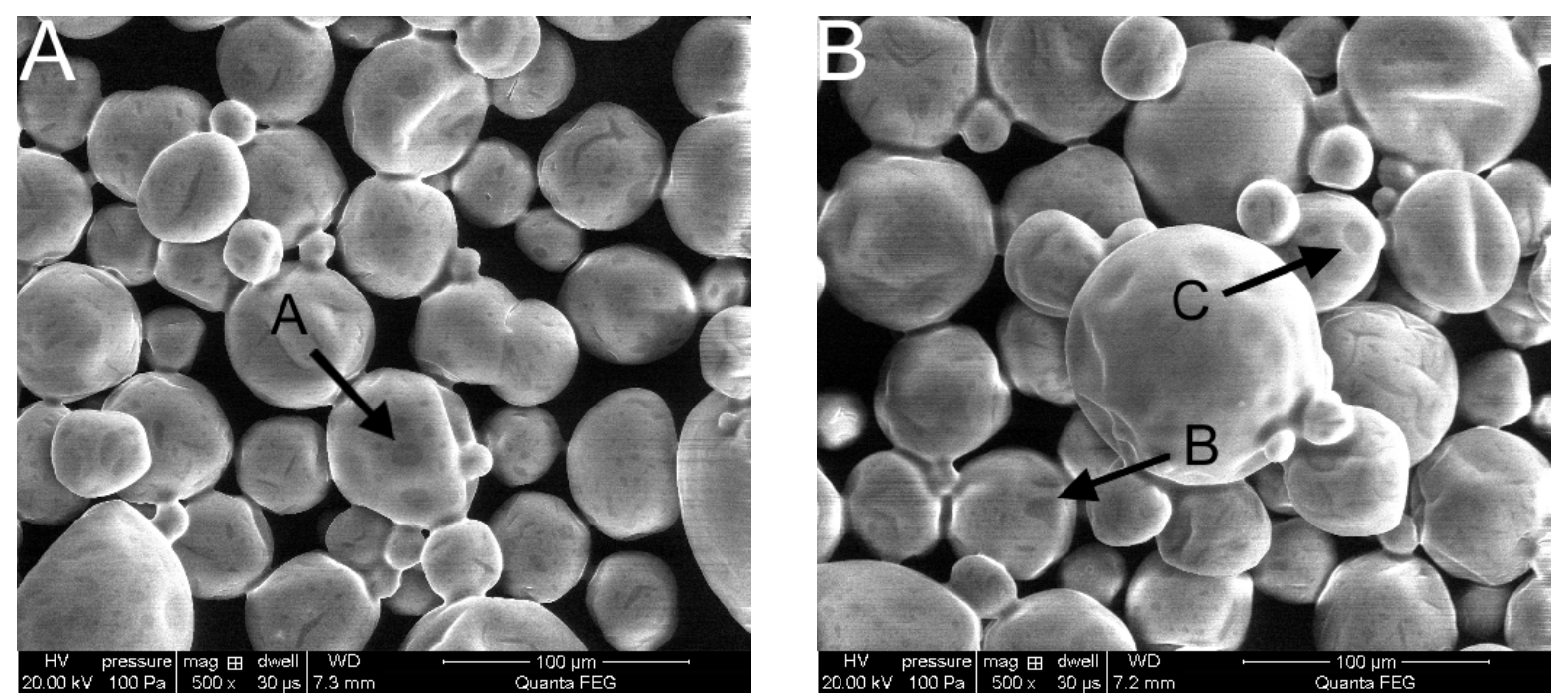

Fig. 2. Morphology of microcapsules obtained during spray drying without foaming, a) $T_{\text {in }}=150^{\circ} \mathrm{C}$, b) $T_{\text {in }}=200^{\circ} \mathrm{C}$ for $Q_{r}=9 \mathrm{~kg} / \mathrm{h}$

The density $\rho_{e}$ changed only within the scope of 1062.5 up to 1072.9 . For the material received during the process of drying several factors have been estimated, among others the apparent density $\rho_{z}$ of the material decreased with air temperature and for the emulsion flow rate of $\sim 9 \mathrm{~kg} / \mathrm{h}$ it was in the range from 1338.2 to $1204.9 \mathrm{~kg} / \mathrm{m}^{3}$ and other. One of the reasons for changes in the apparent density of maltodextrin is particle swelling during high-temperature drying (Zbicinski and Marciniak, 2008). The 
moisture content of the material is a function of drying conditions and was not higher than 0.046 $\mathrm{kg}_{\mathrm{H} 2 \mathrm{O}} / \mathrm{kg}_{\text {dry mass. }}$.

Table 1. Changes of density and microencapsulation efficiency of non-foamed powders

\begin{tabular}{|c|c|c|c|c|c|c|c|c|}
\hline \multirow[t]{2}{*}{ Exp. } & \multirow{2}{*}{$\begin{array}{c}\text { Core/wall } \\
\text { material } \\
\text { ratio } \\
(\mathrm{w} / \mathrm{w})\end{array}$} & \multirow{2}{*}{$\begin{array}{c}\text { Air } \\
\text { temperature } \\
T_{\text {in }} / T_{\text {out }} \\
{\left[{ }^{\circ} \mathrm{C}\right]}\end{array}$} & \multirow{2}{*}{$\begin{array}{c}\text { Emulsion } \\
\text { density } \\
\rho_{e} \\
{\left[\mathrm{~kg} / \mathrm{m}^{3}\right]}\end{array}$} & \multirow{2}{*}{$\begin{array}{c}\text { Apparent } \\
\text { density } \\
\rho_{\text {powder }} \\
{\left[\mathrm{kg} / \mathrm{m}^{3}\right]}\end{array}$} & \multirow{2}{*}{$\begin{array}{c}\text { Efficiency } \\
M e \\
{[\%]}\end{array}$} & \multirow{2}{*}{$\left.\begin{array}{c}\text { Moisture content } \\
X_{\text {powder }} \\
{\left[\mathrm{kg}_{\mathrm{H} 2 \mathrm{O}} / \mathrm{kg}_{\text {dry mass }}\right]}\end{array}\right]$} & \multicolumn{2}{|c|}{$\begin{array}{c}\text { Particle size } \\
\quad[\mu \mathrm{m}]\end{array}$} \\
\hline & & & & & & & $S M D$ & $D_{A M}$ \\
\hline A & $62 / 3$ & $150.9 / 94.2$ & 1072.9 & 1338.2 & 87 & 0.046 & 47.9 & 28.8 \\
\hline B & $62 / 3$ & $175.4 / 86.5$ & 1066.5 & 1318.5 & 65 & 0.041 & 55.1 & 40.2 \\
\hline $\mathrm{C}$ & $62 / 3$ & $204.7 / 114.6$ & 1062.5 & 1204.9 & 75 & 0.019 & 56.1 & 38.4 \\
\hline
\end{tabular}

\subsection{Final products properties obtained from a foamed emulsion}

Table 2 shows changes in the particle diameters depending on the amount of nitrogen injected to the emulsion. We may observe that an addition of the foaming gas in the amount of $0.02 \mathrm{~kg} / \mathrm{h}$ produced visible changes in the volume and shape of the microcapsules maintained between the process of foaming gas and non foaming gas (Tab.1). A higher amount of nitrogen injected into the emulsion (from 0.02 to $0.04 \mathrm{~kg} / \mathrm{h}$ ) caused a small increase in the particles' size (Tab.2) at a constant drying temperature. The presence of nitrogen in the microcapsules generated a gas "cushion", contributing to the formation of particles with a more spherical shape.

Table 2. Changes of density and microencapsulation efficiency of powder with foaming

\begin{tabular}{|c|c|c|c|c|c|c|c|c|c|}
\hline \multirow{2}{*}{ Exp. } & \multirow{2}{*}{$\begin{array}{c}\text { Core/wall } \\
\text { material } \\
\text { ratio } \\
(\mathrm{w} / \mathrm{w})\end{array}$} & \multirow{2}{*}{$\begin{array}{c}\text { Air } \\
\text { temperature } \\
T_{\text {in }} / T_{\text {out }} \\
{\left[{ }^{\circ} \mathrm{C}\right]}\end{array}$} & \multirow{2}{*}{$\begin{array}{c}\text { Foaming } \\
\text { gas flow } \\
Q_{\text {gas }} \\
{[\mathrm{kg} / \mathrm{h}]}\end{array}$} & \multirow{2}{*}{$\begin{array}{c}\text { Emulsion } \\
\text { density } \\
\rho_{e} \\
{\left[\mathrm{~kg} / \mathrm{m}^{3}\right]}\end{array}$} & \multirow{2}{*}{$\begin{array}{c}\text { Apparent } \\
\text { density } \\
\rho_{z} \\
{\left[\mathrm{~kg} / \mathrm{m}^{3}\right]}\end{array}$} & \multirow{2}{*}{$\begin{array}{c}\text { Efficiency } \\
M e \\
{[\%]}\end{array}$} & \multirow{2}{*}{$\begin{array}{c}\text { Moisture } \\
\text { content } \\
X_{\text {powder }} \\
{\left[\mathrm{kg}_{\mathrm{H} 2 \mathrm{O}} / \mathrm{kg}_{\text {dry mass }}\right]}\end{array}$} & \multicolumn{2}{|c|}{$\begin{array}{c}\text { Particle size } \\
{[\mu \mathrm{m}]}\end{array}$} \\
\hline & & & & & & & & $S M D$ & $D_{A M}$ \\
\hline A & $62 / 3$ & $150.1 / 88.3$ & 0.020 & 1009.7 & 811.6 & 82 & 0.017 & 56.1 & 41.6 \\
\hline B & $62 / 3$ & $151.0 / 86.5$ & 0.042 & 788.3 & 801.2 & 79 & 0.024 & 54.8 & 41.5 \\
\hline $\mathrm{C}$ & $62 / 3$ & $151.9 / 79.9$ & 0.075 & 728.7 & 783.6 & 85 & 0.015 & 52.5 & 33 \\
\hline A & $62 / 3$ & $174.6 / 86.3$ & 0.021 & 1001.2 & 650.5 & 85 & 0.015 & 70.1 & 49.5 \\
\hline B & $62 / 3$ & $174.1 / 92.1$ & 0.044 & 783.6 & 615.3 & 70 & 0.011 & 74.5 & 44.1 \\
\hline $\mathrm{C}$ & $62 / 3$ & $175.2 / 87.4$ & 0.075 & 732.6 & 578.2 & 56 & 0.013 & 53.1 & 32.9 \\
\hline A & $62 / 3$ & $204.2 / 125.3$ & 0.021 & 998.6 & 573.2 & 79 & 0.014 & 92.8 & 52.4 \\
\hline B & $62 / 3$ & $201.8 / 118.9$ & 0.044 & 785.4 & 460 & 68 & 0.015 & 98.3 & 53.6 \\
\hline $\mathrm{C}$ & $62 / 3$ & $205.5 / 119.7$ & 0.076 & 702.7 & 417.3 & 52 & 0.011 & 75 & 40.7 \\
\hline
\end{tabular}

However, a further increase of the amount of foaming gas $0.075 \mathrm{~kg} / \mathrm{h}$ caused an increasing degradation of the structure of microcapsules and decreased the mean particles diameter (Table 2). The microencapsulation efficiency for foamed spray decreased from $85 \%$ to $52 \%$ for a higher foaming gas injection rate and higher air temperature. The application of the gas-admixing technique caused a decrease of the microencapsulation efficiency from $6 \%$ for the temperature of $150^{\circ} \mathrm{C}$ and $27 \%$ for the temperature of $200^{\circ} \mathrm{C}$. The increase of the intensity of the gas foaming in the solution caused the decrease of the emulsion density intensity directly affecting the density of the final product for all the temperatures. The presence of a single gas bubble inside the particles was observed. With 
an increased air temperature and gas foaming flow rate we may observe an increase of the mean particle diameters from 41.6 to $53.6 \mu \mathrm{m}$ and $S M D$ from 54.8 to $98.3 \mu \mathrm{m}$. The change of particle diameter was caused by an increase of the volume of gas trapped in the particle. An increase of the temperature of the gas particles inside improved the shape of the microcapsules.
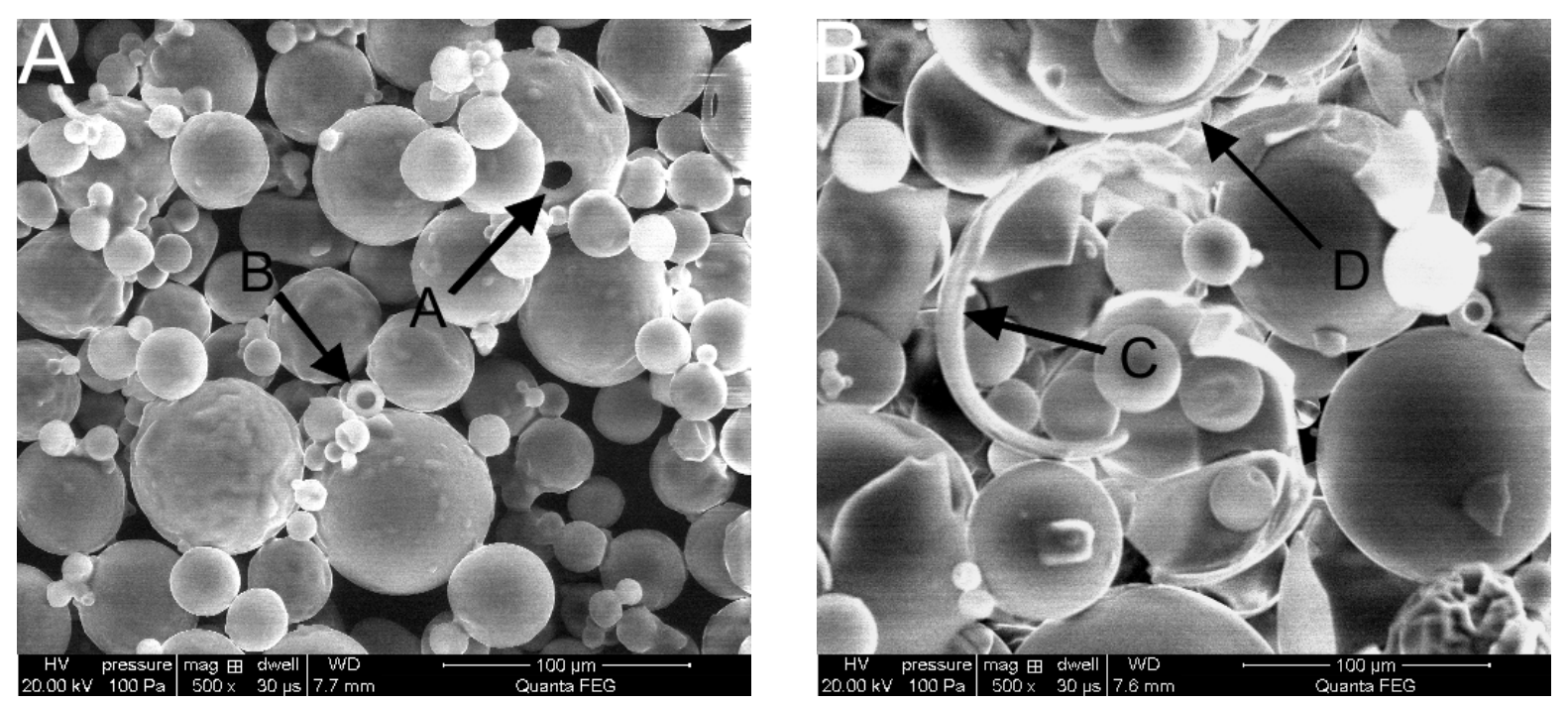

Fig. 3. Morphology of the microcapsules obtained during spray drying with the addition of foaming gas, a) $\left.T_{\text {in }}=150^{\circ} \mathrm{C}, Q_{\text {gas }}=0.04 \mathrm{~kg} / \mathrm{h}, \mathrm{b}\right) T_{\text {in }}=200^{\circ} \mathrm{C}, Q_{\text {gas }}=0.04 \mathrm{~kg} / \mathrm{h}$

Figure $3(\mathrm{a}, \mathrm{b})$ shows powder morphology at the temperatures $T_{\text {in }} / T_{\text {out }}=(151 \pm 1.7 / 86 \pm 2.1)^{\circ} \mathrm{C}$ and $T_{\text {in }} / T_{\text {out }}=(201 \pm 2.4 / 119 \pm 1.3)^{\circ} \mathrm{C}$ at the same amount of nitrogen added. It has been observed that the particles had more regular shapes when compared to the particles obtained out of the emulsion that was not foamed. An increase of the flow intensity of the gas added to the emulsion triggered off an increase in the amount of particles with holes in the walls (Fig. 3a, b; point A and B), which unfavourably affected microencapsulation. Simultaneously, for a higher drying temperature, an increase of the participation of the broken particles has been observed. An analysis of the photographs shows that the addition of the foaming gas leads to the formation of microcapsules with thinner walls. The wall thickness of microcapsules changed from 10 to $2 \mu \mathrm{m}$.

Increasing the foaming gas flow rate resulted in a sharp change in the apparent density of powders from 1330.2 to $811.6 \mathrm{~kg} / \mathrm{m}^{3}$. Foaming of the emulsion resulted in obtaining powders characterised by lower apparent density, due to the expansion of gas bubbles trapped inside the emulsion droplet. An additional factor influencing the decrease in apparent density of the powder was the increase of cracked microcapsules (Schoonman et al., 2001). A comparison of the apparent density of powders for foamed and non-foamed emulsions (Tables 1 and 2) shows that the crucial factor responsible for such a large change in the apparent density of powders is the flow rate of foaming gas and the temperature of drying air.

\section{SUMMARY AND CONCLUSIONS}

The properties of foamed and the non-foamed spray-dried product and microencapsulation efficiency were determined experimentally. The analysis of the apparent density of powders for different foaming rates showed that the foaming process reduced powder density by $50 \%$ in comparison with the powder produced from a non-foamed emulsion. The results show that the foaming process of the emulsion did not affect significantly the efficiency of microencapsulation which was around $\sim 70 \%$. Despite a decrease of the wall thickness, microencapsulation efficiency remained high. 
An addition of 0.02 to $0.075 \mathrm{~kg} / \mathrm{h}$ of foaming gas and an increase of the drying temperature from 150 to $200^{\circ} \mathrm{C}$ contributed to an increase in the mean particle diameter and Sauter diameter and arithmetic mean particle diameters.

Foaming of the emulsion enabled control of the apparent density of the powders retaining high efficiency of spray drying in the microencapsulation process.

The study was supported by Grant No. 2011/35 from the Technical University of Lodz.

\section{SYMBOLS}

$\begin{array}{ll}D_{A M} & \text { arithmetic mean diameter, } \mu \mathrm{m} \\ M e & \text { microencapsulation efficiency, } \% \\ Q_{\text {gas }} & \text { foaming gas flow rate (nitrogen), } \mathrm{kg} / \mathrm{h} \\ Q_{\text {Air }} & \text { drying air flow rate, } \mathrm{Nm}{ }^{3} / \mathrm{h} \\ Q_{r} & \text { emulsion flow, } \mathrm{kg} / \mathrm{h} \\ S E M & \text { Scanning Electron Microscopy } \\ S M D & \text { Sauter Mean Diameter, } \mu \mathrm{m} \\ T_{r} & \text { temperature in the tank, }{ }^{\circ} \mathrm{C} \\ T_{\text {in }} & \text { inlet air temperature, }{ }^{\circ} \mathrm{C} \\ T_{\text {out }} & \text { outlet air temperature, }{ }^{\circ} \mathrm{C} \\ X_{\text {powder }} & \text { moisture content of the material, } \mathrm{kg}_{\mathrm{H} 2 \mathrm{O}} / \mathrm{kg}_{\text {dry mass }}\end{array}$

Greek symbols

$\rho_{\text {liquid }+ \text { gas }} \quad$ emulsion density with gas, $\mathrm{kg} / \mathrm{m}^{3}$

$\rho_{e} \quad$ emulsion density, $\mathrm{kg} / \mathrm{m}^{3}$

$\rho_{z} \quad$ apparent density of the material, $\mathrm{kg} / \mathrm{m}^{3}$

\section{REFERENCES}

Adamiec J., Marciniak E., 2006. Study on the kinetics of simultaneous drying and microencapsulation in a spray dryer. Chem. Process Eng., 27, 535-546 (in Polish).

Benita S., 2006. Microencapsulation: methods and industrial applications. Taylor \& Francis, Boca Raton, USA.

Chen A.Z., Li Y., Foo-Tim C., Tsui-Yan L., Jun-Yan H., Zheng Z. D., Kam-Wah M., 2009. Microencapsulation of puerarin nanoparticles by poly(L-lactide) in a supercritical $\mathrm{CO}_{2}$ process. Acta Biomaterialia, 5, $2913-2919$.

Gibbs B.F., Kermasha S., Alli I., Mulligan C.N., 1999. Encapsulation in the food industry: A review. Int. J. Food Sci. Nutrition, 50, 213-224. DOI: 10.1080/096374899101256.

Fuchs M., Turchiuli C., Bohin M., Cuvelier M.E., Ordonnaud C., Peyrat-Maillard M.N., Dumoulin E., 2006. Encapsulation of oil in powder using spray drying and fluidised bed agglomeration. J. Food Eng., 75, $27-35$. DOI: $10.1016 /$ j.jfoodeng.2005.03.047.

Hanrahan F.P., Tamsma A., Fox K.K., 1962. Production and Properties of Spray Dried Whole Milk, J. Dairy Sci., 45, 27-31.

Hanrahan F.P., Webb B.H., 1961. Foam spray drying methods of making readily dispersible non-fat dry milk. Food Eng., 33 8, 36-38.

Kumar S.G., 2006. Functional coatings: by polymer microencapsulation. Wiley-VCH, Germany.

Mongenot N., Charrier S., Chalier P., 2000. Effect of ultrasound emulsification on cheese aroma encapsulation by carbohydrates. J. Agric. Food Chem., 48, 861-867. DOI: 10.1021/jf990494n. 
Schoonman A.G., Mayor M.-L., Dillmann Ch., Bisperink J.U., 2001. The microstructure of foamed maltodextrin/sodium caseinate powders: A comparative study by microscopy and physical techniques. Food Res. Int., 34, 913-929. DOI: 10.1016/S0963-9969(01)00116-8.

Zuidan N.J., Nedović V., 2010. Encapsulation technologies for active food ingredients and food processing, Springer-Verlag, Berlin.

Zbicinski I., Marciniak E., 2008. Microencapsulation in spray drying - an overview. 16th International Drying Symposium (IDS 2008), A, 9-12. India, Hyderabad. 